 \\ Вербальные приемы фасцинации во французских кинотекстах
}

Ткачева А. Н.

\begin{abstract}
Аннотация. Цель статьи - выявление вербальных приемов фасцинации во французских кинотекстах. Научная новизна работы состоит в том, что в ней впервые описаны вербальные приемы во французских кинотекстах, которые оказывают фасцинативное воздействие на публику. Выявлено, что языковая игра, английские слова активизируют интерес реципиентов необходимостью декодирования и интерпретации; лексические повторы, антитеза фиксируют внимание, улучшают запоминание; названия с директивами, вопросами и восклицаниями создают психологический контакт, передают эмоциональное возбуждение. Выразительные средства языка воздействуют на эффективность восприятия заголовка, вовлекают зрителя в сюжет фильма.
\end{abstract}

\section{EN Verbal Devices of Fascination in the French Film Texts}

\author{
Tkacheva A. N.
}

\begin{abstract}
The purpose of the article is to identify verbal devices of fascination in the French film texts. The study is novel in that it is the first to describe verbal devices in the French film texts that have a fascination effect on the public. It is found that the language play, the English words activate recipients' interest through the need for decoding and interpretation; lexical repetitions, the antithesis concentrate attention, improve memory retention; titles containing instructions, questions and exclamations establish psychological contact, convey emotional excitement. Expressive means of language influence effectiveness of perceiving a title, involve a viewer in the plot of a film.
\end{abstract}

\section{Введение}

Современный кинематограф характеризуется массовым производством фильмов. Вопросы влияния на зрительскую публику стоят очень остро. Кинопроизводители стремятся любыми оригинальными средствами заинтересовать и удержать потенциального зрителя. В конкурентной борьбе за публику все чаще используются приемы фасцинации. Под фасцинацией подразумевается «способность внешней формы... приковывать внимание, вызывать волнующий интерес, удивление, радость, восторг, очарование, экстаз, шок, испуг, ужас» [13, с. 8]. Цель фасцинации - повлиять на поведение, сознание, подсознание адресатов через их эмоциональную сферу [14, с. 31]. Разнообразные приемы фасцинации (вербальные, звуковые, поведенческие, изобразительные) широко применяются в рекламе [7], средствах массовой информации [3; 12], кинопроизведениях [9], педагогической и политической коммуникации [14] и т.д. Вербальные приемы фасцинации, используемые в текстах разной направленности (пресса, литература, реклама, песни), основаны на нарушении общепринятых языковых норм, в результате чего удается привлечь, развлечь и удержать внимание целевой аудитории [2, с. 963].

В настоящее время вербальные фасцинативные приемы в коммуникации и рекламе широко обсуждаются в связи с необходимостью поиска новых эффективных средств речевого воздействия на сознание и поведение адресатов. В данной работе будут рассмотрены некоторые вербальные фасцинативные средства, которые получили устойчивое использование во французских заголовочных кинотекстах. Актуальность работы обусловлена двумя причинами: 1) растущим научным интересом к изучению феномена фасцинации и средств ее реализации в различных видах коммуникации; 2) незатухающим интересом к киноназваниям с точки зрения их роли в успешном принятии фильма в социокультурном пространстве. Объектом данной работы являются французские кинозаголовки. Предмет исследования - вербальные приемы фасцинации.

Достижение поставленной цели осуществляется при помощи решения следующих задач: 1) выявить во французских кинотекстах основные лексические и грамматические средства французского языка, приводящие к фасцинативному воздействию на зрительскую публику; 2) описать фасцинативную нагрузку лексических и грамматических средств. В процессе исследования применялись методы лингвистического наблюдения и описания. Метод сплошной выборки применялся при отборе фактического материала. 
Теоретической базой исследования послужили труды Л. В. Козяревич [6], Е. В. Омельченко [9], В. М. Соковнина [13], В. Д. Ширшова [14], посвященные фасцинативным воздействующим явлениям в различных сферах человеческого общения, а также работы Е. И. Абрамовой [2], Т. А. Костроминой [7], М. В. Поварницыной [11], А. Ш. Сафаргалиной [12], посвященные вербальным средствам фасцинации в текстах СМИ и рекламы.

Практическая значимость: полученные данные могут найти применение в вузовской практике при обучении французскому и русскому языкам, культуре речи, психологии массовых коммуникаций, организации рекламных и PR-кампаний, в спецкурсах и спецсеминарах по ораторскому мастерству и речевым приемам в публичном выступлении.

Для исследовательского материала были выбраны 100 франкоязычных заголовков с сайта kinopoisk.ru [5]. В результате анализа были выделены группы вербальных фасцинативных средств, которые регулярно используются во французских кинотекстах.

\section{Вербальные приемы фасцинации во французских кинотекстах}

Современные кинематографисты вынуждены бороться за зрительскую аудиторию из-за обилия существующей кинопродукции. Современное кинопотребление организовано таким образом, что в первую очередь потенциальный зритель воспринимает заголовок и только потом, в случае заинтересованности, приступает к просмотру киноленты. Как следствие, все названия картин, помимо номинативной (именования и идентификации) и информативной (содержательной) функций, выполняют аттрактивную или рекламную функцию, которая заключается в привлечении публики. При этом, как правило, рекламная функция сопровождается функцией воздействия.

Заголовочные тексты французских фильмов обогащаются вербальными фасцинативными сигналами, позволяющими повлиять на поведение и выбор реципиента через психологическое возбуждение. Фасцинативность текста - это совокупность характеристик, «превращающих этот текст в объект притяжения для адресата» [11, с. 120]. Фасцинативные тексты «наделены особыми навязчиво заметными признаками: яркость, экспрессия и особая энергетика, красочность, заметность, избыточность, эксклюзивность, повелительность, императивность» [6, с. 138]. Можно утверждать, что фасцинативные заголовочные тексты - это избыточно экспрессивные яркие названия со специально организованным вербальным (словесным) воздействием на адресата. Они выигрышно отличаются от малопривлекательных стилистически нейтральных заголовочных текстов.

В качестве приемов фасцинации в заголовочных кинотекстах успешно применяются многие естественноязыковые средства, вызывающие у реципиентов интенсивные эмоции. Наиболее распространенными механизмами воздействия на публику являются: языковая игра, английские слова, антитеза, лексический повтор, экспрессивный синтаксис. Ниже будет подробно описана их фасцинативная нагрузка в кинотекстах, а также будут приведены примеры.

\section{Фасцинативная нагрузка вербальных приемов}

\section{1. Идеографизация и языковая игра}

Целый ряд французских кинокартин имеют зрелищные и броские заглавия благодаря идеографизации, т.е. использованию в качестве словообразования условного и общеизвестного знака, например:

- “L’@mour est à réinventer” («Любовь должна быть придумана заново») (реж. М. Аллуаш, 1996);

- “Juste un peu d’@mour” («Просто немного любви») (реж. Н. Хердт, 2009);

- “Alibi.com” («Супералиби») (реж. Ф. Лашо, 2017).

Знак “@” является символом электронной почты, а знак “.com” - символом интернет-сайта. В завуалированной форме названия указывают на то, что сюжеты картин связаны с виртуальными любовными отношениями. Использование компьютерных символов продиктовано стремлением авторов к креативности и следованию языковой моде с целью привлечения целевой аудитории [3, с. 183]. Названия получились нетривиальными, остроумными.

Также красив заголовок картины “Un prince (presque) charmant” («(Не)жданный принц») (реж. Ф. Леллуш, 2013), который буквально переводится как «Принц (почти) очаровательный». Слово “presque” («почти») в скобках ставит постулат об очаровательности принца под сомнение.

Языковая игра, при которой языковые единицы творчески и нестандартно используются, придает дополнительную экспрессию и обладает определенным эффектом воздействия [1, с. 7]. Парадоксальное использование языковых средств интенсифицирует восприятие публики, поскольку люди любят все новое и необычное. Декодирование слов и знаков удерживает внимание реципиента, который к тому же получает эстетическое наслаждение от самостоятельного поиска и последующей творческой интерпретации авторской задумки [9, с. 50].

Языковая игра забавляет, если приводит к юмористической окраске названий. Так, шутливое название комедии “Liberté, égalité, choucroute” («Свобода, равенство, кислая капуста») (реж. Ж. Янн, 1985) обыгрывает национальный французский девиз “Liberté, égalité, fraternité” («Свобода, равенство, братство»), который был искажен заменой слова “fraternité” («братство») словом “choucroute” («кислая капуста»). Шутка, как креативный фасцинативный прием, формирует позитивный образ киноленты, развлекает, улучшает настроение публики. 


\section{2. Английские слова}

К приемам фасцинации можно отнести использование английской лексики. Английский язык является в настоящее время основным источником заимствований для многих языков, что связано с его использованием как средства международного общения. Французы часто с удовольствием употребляют привлекательные английские слова, хотя и считают, что англицизмы «засоряют» родной язык. Однако приток заимствований нельзя воспринимать сугубо в негативном ключе. Преднамеренное употребление общеизвестных и общеупотребительных слов английского языка вместо франкоязычных аналогов провоцирует любопытство публики. Названия с «чужими» словами выделяются своей оригинальной буквенной записью, выполняя в первую очередь декоративную функцию. Названия влияют на воображение и ум людей, поскольку они состоят из иностранных слов с нестандартной для принимающей лингвистической среды формой написания букв. Зрителям предстоит самостоятельно перевести заголовочный текст:

- “Skate or Die” («На скейте от смерти») (реж. М. Куртуа, 2008);

- “Rapt” («Похищение») (реж. Л. Больво, 2009);

- “Jessica Forever” («Джессика навсегда») (реж. К. Поджи, 2018).

Вводимые слова, которые сохраняют семантику языка-источника, понятны вследствие высокой частотности их употребления во франкофонном пространстве. При этом они, будучи иноязычными словами, вносят дополнительные смыслы и оттенки в основной смысл. Так, иноязычные слова могут быть средством сатирической характеристики и критического отношения автора к персонажу. Авторы кинолент “Darling” («Дорогая») (реж. К. Картье, 2007) и “Нell” («Ад») (реж. Б. Шиш, 2006) выносят в названия прозвища главных героев, иронизируя над ними.

Перевод, истолкование требуют дополнительных усилий со стороны зрительской аудитории, втягивают в процесс отгадывания. Иноязычные слова, как нестандартная лексика, используются, чтобы развлечь или «встряхнуть» адресата, утомленного однообразным стилем передачи информации [12, с. 321].

\section{3. Лексический повтор}

К фасцинативным приемам следует причислить повтор лексических единиц. Повторяемость способна «создавать эффект завораживания, затягивания, эмоционального кружения» [9, с. 50]. Лексический повтор применяется в основном для усиления экспрессивности, для привлечения внимания и бо́льшей запоминаемости [1, с. 9]. Повторы повсеместно представлены в заголовочных французских текстах:

- "La belle et la belle” («Марго и Марго») (реж. С. Фийер, 2018);

- “Valentin Valentin” («Валентин, Валентин») (реж. П. Тома, 2014);

- “Donnant, donnant” («Услуга за услугу») (реж. И. Мерго, 2010).

Повторяемое слово акцентирует внимание на себе, заставляет задуматься о его смысле, вызывает в сознании ряд ассоциаций: “Тrop c’est trop” («Слишком - это слишком») (реж. Д. Каминка, 1975). Повтор усиливает эмоционально-смысловое восприятие заголовка реципиентом.

\section{4. Антитеза}

Некоторые заголовочные тексты строятся на смысловой противоположности антонимов. Противопоставление создает для фильма эффект преимущества, уникальности или отличительной особенности [4, с. 213]. Прием, основанный на контрасте двух противоположных, но связанных понятий, создает стилистический эффект, широко используется, поскольку хорошо выделяется и легко запоминается [1, с. 11]. В названиях противопоставляются разные части речи:

- “Pars vite et reviens tard” («Семена смерти») (реж. Р. Варнье, 2007);

- “L’un reste, l’autre part” («Один уходит, другой - остается») (реж. К. Берри, 2005);

- “Тoi et moi” («Ты и я») (реж. Д. Лопес-Кюрваль, 2006).

Встречаются двойные противопоставления. Так, в названии “Pеau d’homme, cœur de bête” («Шкура человека, сердце зверя») (реж. Х. Энджел, 1999) контрастируют слова “реau” («шкура») и “сœur” («сердце»), “homme” («человек») и “bête” («животное»). В заголовке “Nelly et Monsieur Arnaud” («Нелли и месье Арно») (реж. К. Соте, 1995) противопоставлены женщина и мужчина, имя и фамилия. Воздействующий эффект от суммы двух контрастов возрастает.

В заголовочном тексте могут применяться сразу несколько приемов, как, например: “Тelle mère, telle fille” («Ой, мамочки») (реж. Н. Сальо, 2017). Одновременное использование повтора (“telle” и “telle”) и антитезы (“mère” и "fille”) усиливает эмоциональное влияние на адресата.

\section{5. Экспрессивный синтаксис}

Киноназвания с экспрессивным синтаксисом являются эффективным способом притяжения публики. Вопросы, приказы и восклицания привлекательны, прежде всего, своей формой. Обладая дополнительными экспрессивными знаками, заголовки выигрышно отличаются от стилистически нейтральных заголовков:

- “Au secours, j’ai 30 ans!” («Караул, мне 30 лет!») (реж. М.-А. Шазель, 2004);

- “Combien tu m’aimes?” («Сколько ты стоишь?») (реж. Б. Блие, 2005);

- “Faut que ça danse!” («И пусть все пляшет!») (реж. Н. Львовски, 2007).

Вопросы вовлекают публику в совместное размышление, диалог, требуя ответа на поставленный в заголовке вопрос. В триллере “Qui a tué Bambi?” («Кто убил Бэмби?») (реж. Ж. Маршан, 2003) изображается героиня по имени Бэмби, которую по сюжету кто-то стремится убить. В комедийном детективе "Mais qui a tué Pamela Rose?” («Кто грохнул Памелу?») (реж. Э. Лартиго, 2003) полицейские расследуют убийство молодой стриптизерши. Прямые вопросы заинтриговывают реципиента, «поскольку от него требуется непосредственное участие в поиске ответа на вопрос» [7, с. 150]. 
Директивы выражают душевные переживания и настроение персонажей. Названия с побуждениями вовлекают зрителя в ситуацию, переживаемую героем или героиней [10, с. 835]. В детективе “Arrêtez-moi” («Арестуйте меня») (реж. Ж.-П. Лильенфельд, 2013) героиня делает чистосердечное признание в полицейском участке и просит ее арестовать. Драма “Tiens-toi droite” («Держись прямо») (реж. К. Левкович, 2014) изображает девушку, которая испытывает сильнейшее давление общества, отстаивая свою независимость.

Восклицания выражают сильные эмоции:

- восхищение: “Palais Royal!” («Королевский дворец!») (реж. В. Лемерсье, 2005);

- раздражение или гнев: “Radin!” («Жмот») (реж. Ф. Кавайе, 2016);

- радость: “En liberte!” («Нежная рука закона») (реж. П. Сальвадори, 2018).

Киноназвания с восклицательными, вопросительными, побудительными предложениями интригуют аудиторию, поскольку они содержат мало информации относительно сюжета картин. Неоднозначные, непонятные заголовки вызывают любопытство, заставляя аудиторию обращаться к рекламным роликам (трейлерам), постерам, слоганам. Часто единственным способом понимания смысла названия становится просмотр картины:

“C’est le bouquet!” («Вам букет!») (реж. Ж. Лабрюн, 2002);

“Fais-moi plaisir” («Доставь мне удовольствие») (реж. Э. Муре, 2009);

“Tu peux garder un secret?” («Ты можешь хранить тайну?») (реж. А. Аркади, 2008).

Если нейтральный заголовок обращается к интеллекту, то экспрессивно-эмоциональные заголовки направлены на возбуждение эмоциональной сферы. Основное назначение экспрессивного синтаксиса - задеть за живое зрителя, создать психологический контакт, заинтересовать. Самым проверенным и безошибочным методом воздействия на человеческое сознание продолжает оставаться обращение к эмоциям и чувствам [8, с. 33].

Посредством прямого обращения французские заголовки с экспрессивным синтаксисом вовлекают зрителя в сюжет киноленты через эмоциональную реакцию. Директивы и вопросы создают игровой эффект, а восклицания передают эмоциональное возбуждение.

\section{Заключение}

Итак, в ходе работы были сделаны следующие выводы.

1. Вербальными фасцинативными приемами во французских кинотекстах следует признать языковую игру, английские слова, антитезу, лексический повтор, экспрессивный синтаксис.

2. Языковая игра и английские слова стимулируют творческие усилия со стороны языковой личности, которая вынуждена декодировать высказывание, вникнуть в его смысл. Антитеза и лексические повторы фиксируют внимание, улучшают запоминание. Экспрессивный синтаксис создает психологический контакт, порождает симпатию. Все описанные лексические и грамматические средства французского языка воздействуют на эффективность восприятия, обостряют внимание, вовлекают зрительскую публику в сюжет фильма.

Перспективы дальнейших исследований обусловлены возможностью последующего анализа аудиовизуальных и визуальных (графических) элементов французских кинотекстов в целях выявления в них фасцинативных приемов на невербальном уровне.

\section{Список источников}

1. Абрамов В. Е. Лингвистика рекламной языковой игры // Вестник Челябинского государственного университета. 2019. № 4 (426). С. 7-13.

2. Абрамова Е. И. Фасцинативные приемы в текстах языкового ландшафта // Коммуникативные исследования. 2019. Т. 6. № 4. С. 961-973.

3. Гапутина В. А. Приемы фасцинации в заголовках глянцевых медиа // Коммуникативные стратегии информационного общества: труды XII Международной научно-теоретической конференции. СПб.: ПОЛИТЕХПРЕСС, 2020. С. 181-185.

4. Грибова М. В. Противопоставление как один из приемов языкового манипулирования в рекламе // Социальноэкономические явления и процессы. 2011. № 8 (30). С. 210-213.

5. КиноПоиск [Электронный ресурc]. URL: https://www.kinopoisk.ru/ (дата обращения: 14.01.2021).

6. Козяревич Л. В. Фасцинация и эмпатия в аспекте перевода как категории коммуникации // Вестник Московского государственного лингвистического университета. 2013. № 9 (669). С. 136-143.

7. Костромина Т. А. Фасцинация в креолизированных текстах англоязычной социальной рекламы // Верхневолжский филологический вестник. 2018. № 3. С. 145-154.

8. Крутова И. Н. Заголовок публицистического текста как формирующий регулянт эмотивно-дискурсивного пространства // Гуманитарные исследования. 2018. № 4 (68). С. 32-36.

9. Омельченко Е. В. Нейроэстетика и фасцинация в восприятии художественных явлений (на примере фильма «Ла-Ла Ленд») // Челябинский гуманитарий. 2017. № 4 (41). С. 50-55.

10. Панкратова С. А. Диалогическая природа локализованных киноназваний // Вестник Кемеровского государственного университета. 2019. Т. 21. № 3 (79). С. 830-838.

11. Поварницына М. В. Манипуляция, суггестия, аттракция и фасцинация в креолизованном тексте // Известия Волгоградского государственного педагогического университета. 2016. № 2 (106). С. 117-124. 
12. Сафаргалина А. Ш. Типы фасцинации и средства ее реализации в языке средств массовой коммуникации // Вестник Башкирского университета. 2008. Т. 13. № 2. С. 320-323.

13. Соковнин В. М. Коммуникативное фасцинирующее нацеливание (fascino targeted communication) - главная функция фасцинации // Метеор-Сити. 2016. № 2. С. 7-43.

14. Ширшов В. Д. Знаки фасцинации в педагогической коммуникации // Образование и наука. Известия УрО РАО. 2004. № 1 (25). С. 29-36.

\section{Информация об авторах | Author information}

RU Tкачева Анна Николаевна ${ }^{1}$, к. филол. н., доц.

${ }^{1}$ Санкт-Петербургский государственный институт кино и телевидения

EN Tkacheva Anna Nikolaevna ${ }^{1}, \mathrm{PhD}$

${ }^{1}$ St. Petersburg State University of Film and Television

${ }^{1}$ Tkatcheva-Ann@yandex.ru

\section{Информация о статье | About this article}

Дата поступления рукописи (received): 10.01.2021; опубликовано (published): 26.02.2021.

Ключевые слова (keywords): языковая игра; французский заголовок; экспрессивный синтаксис; фасцинативный прием; language play; French title; expressive syntax; fascination device. 